\title{
OS SABORES DO/NO RIO ARAÍ
}

\author{
Miguel de NAZARÉ Brito PICANÇO ${ }^{1}$
}

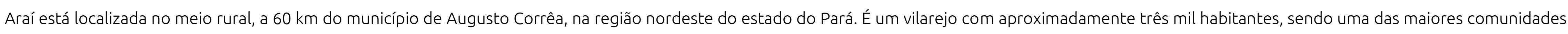

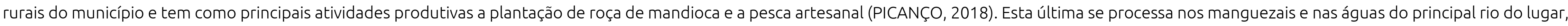

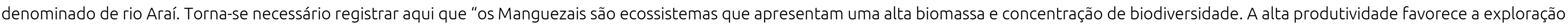

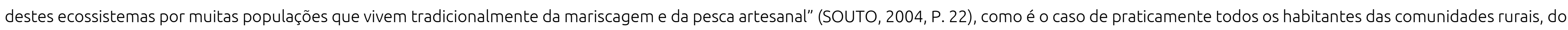

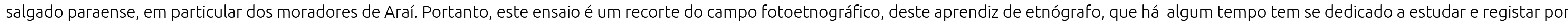

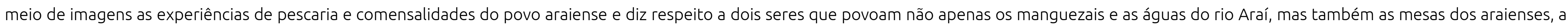
saber: o baiacu (tetraodontídeos) e o turu (Teredo navalis).

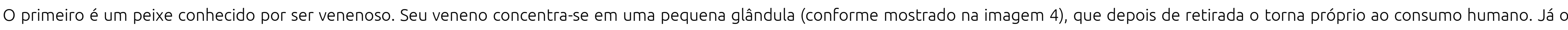

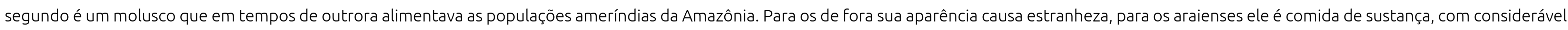

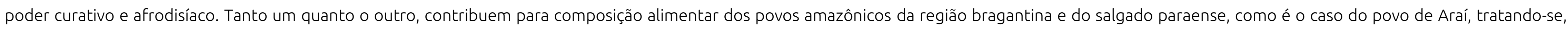
assim, de uma linguagem de identidade (MACIEL, 2005, CONTRERAS, 1992), de um povo caboclo e amazônico. 


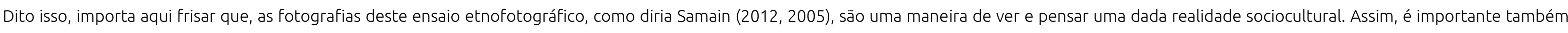

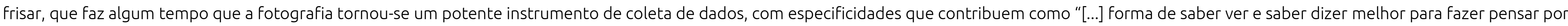

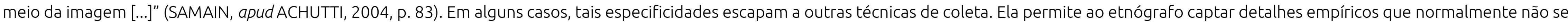

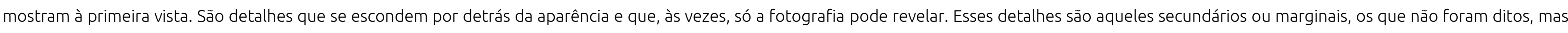
que podem ser decisivos para o trabalho do etnógrafo.

Assim, as imagens deste ensaio são autônomas, "pensam" e nos fazem pensar sobre o modo singular de pescar e comer, dos pescadores do rio Araí. 


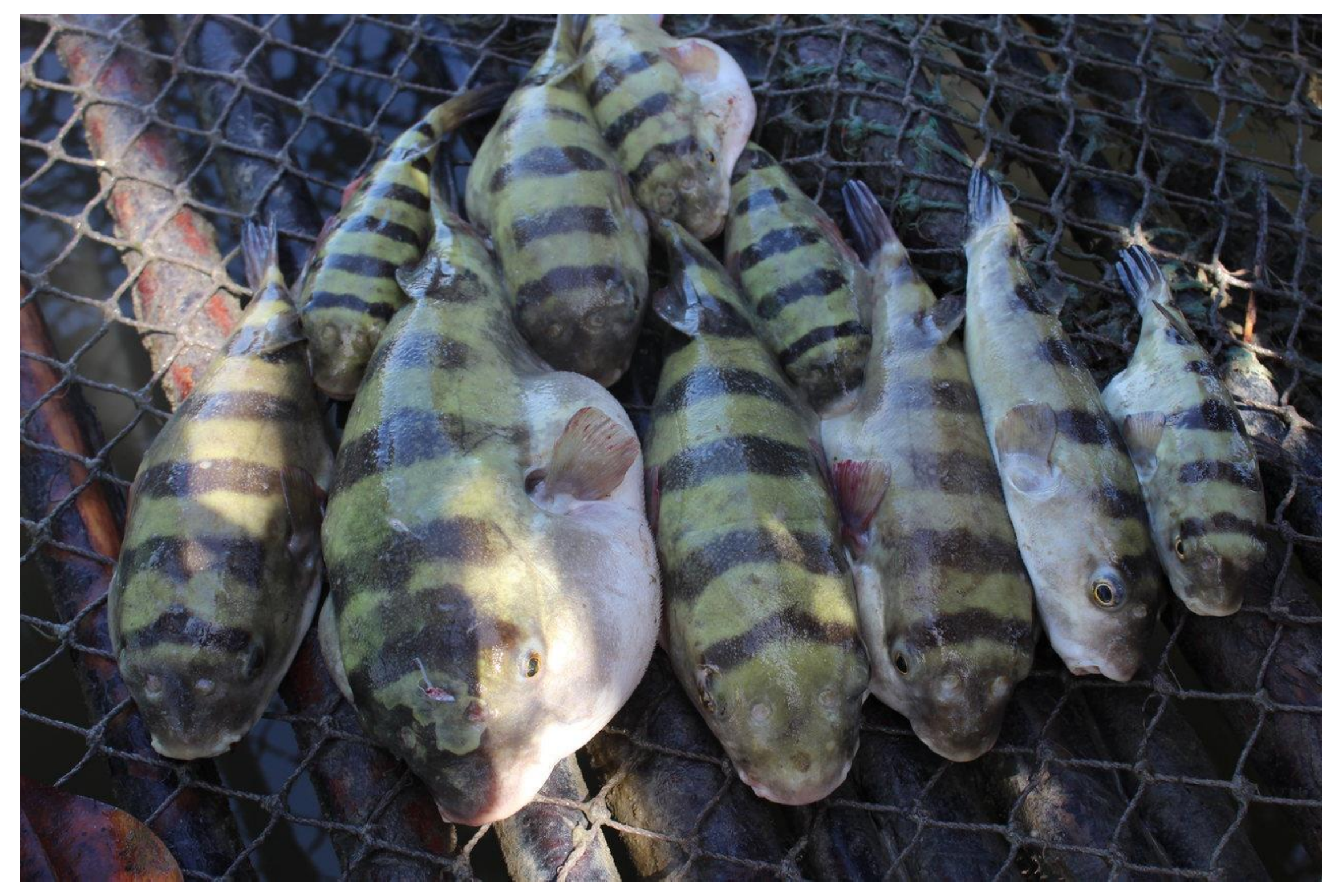



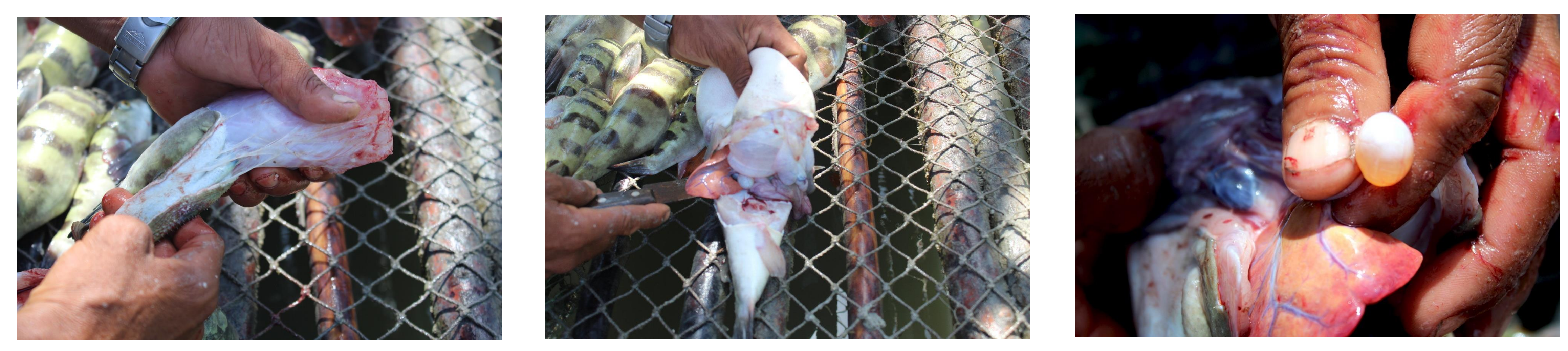



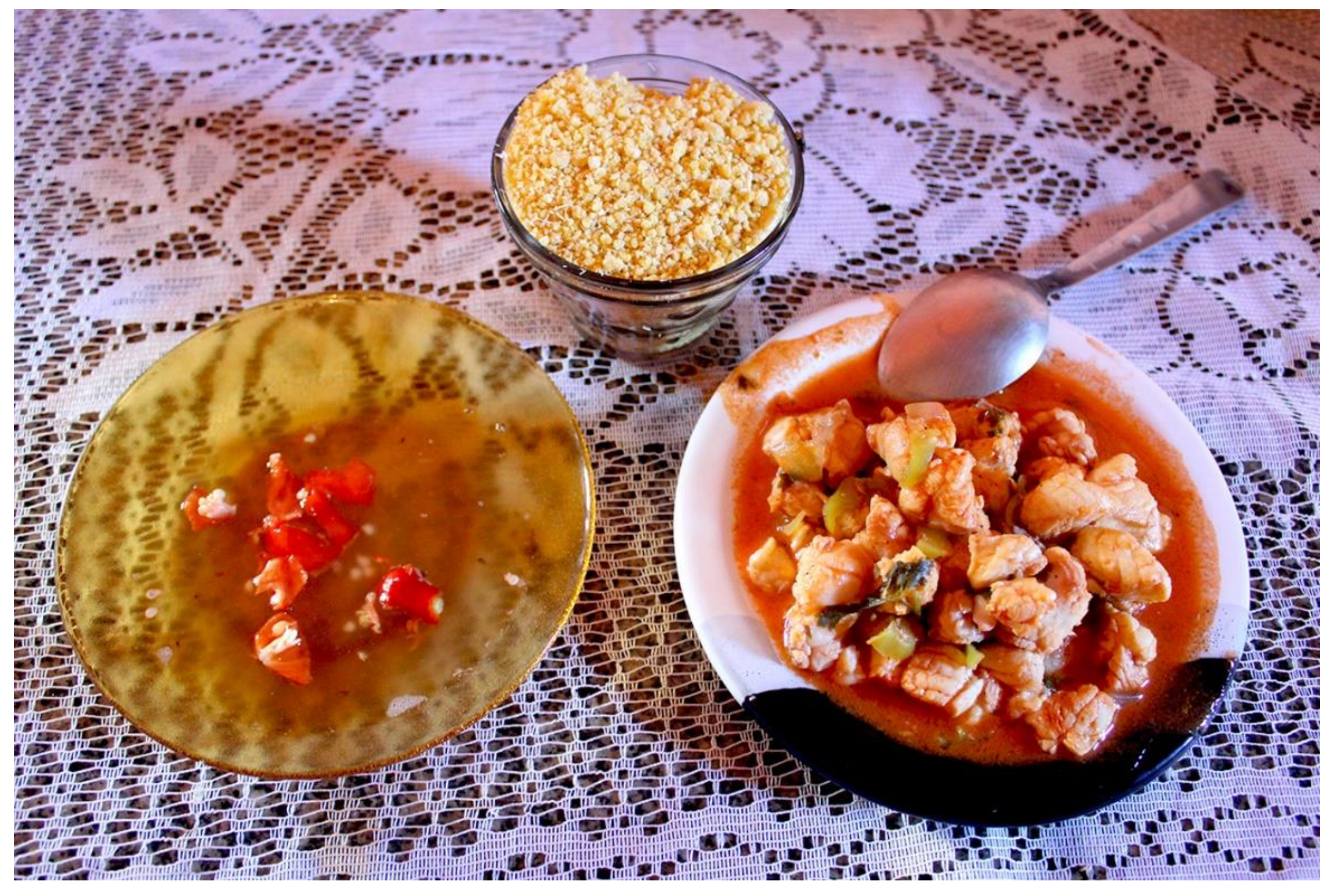




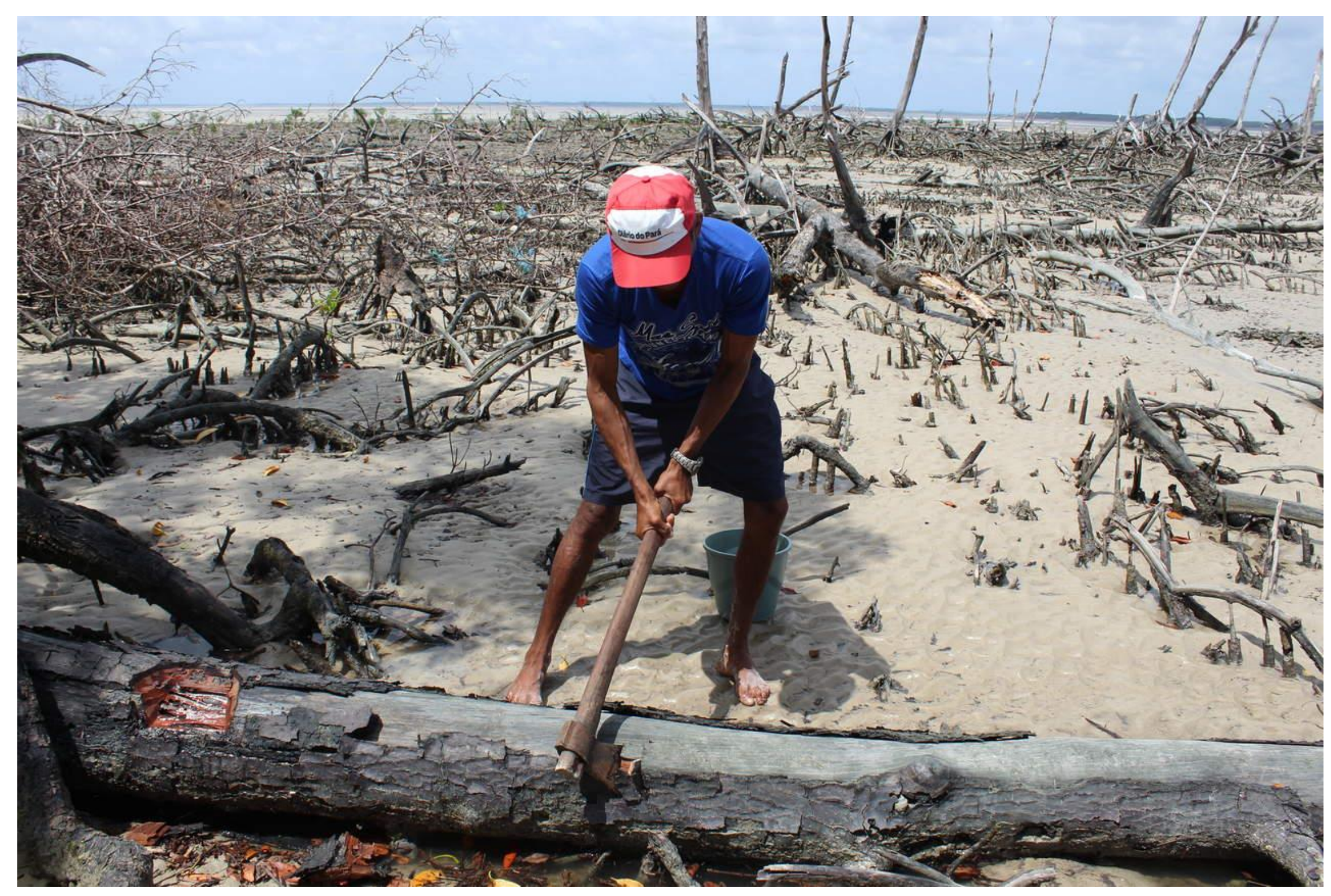



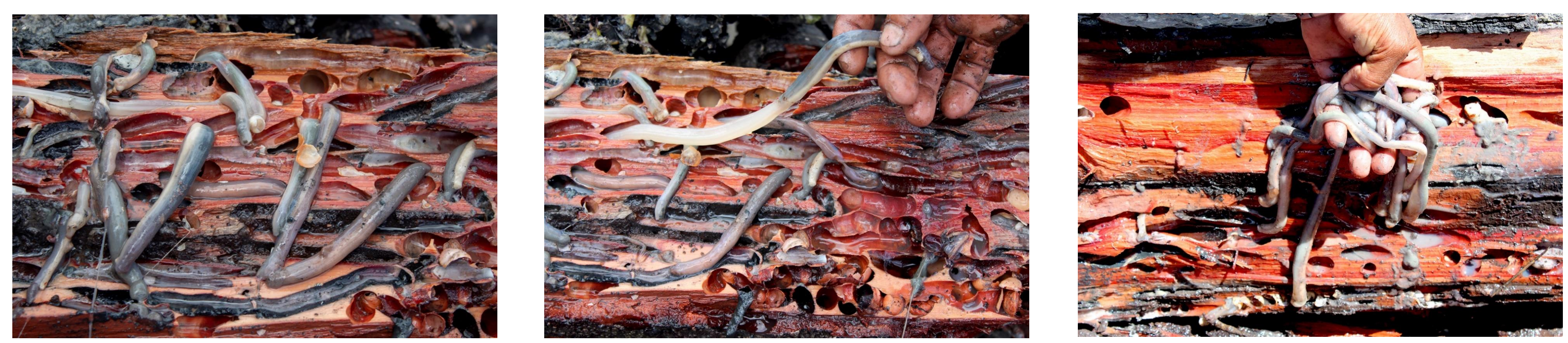


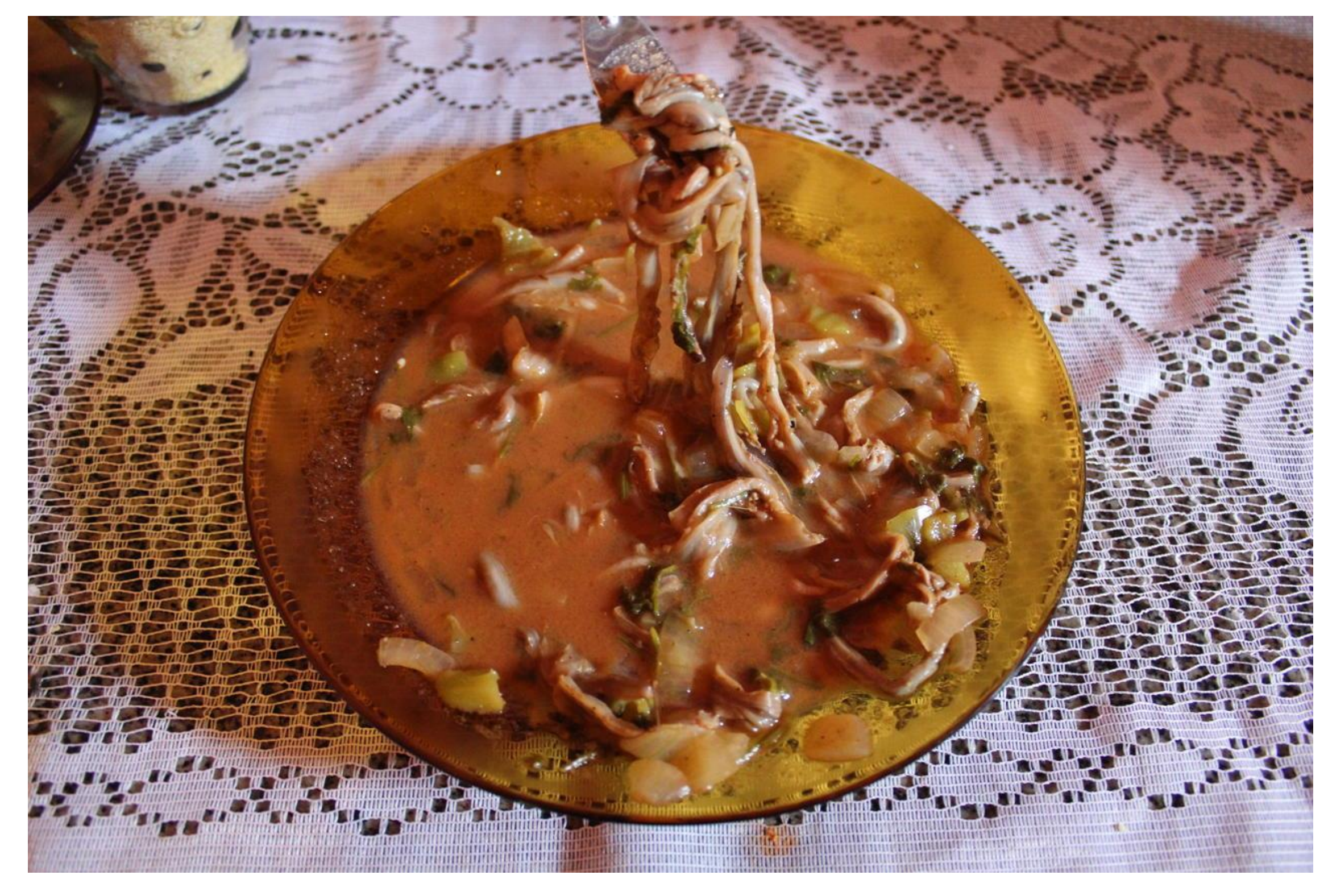


ACHUTTI, Luiz Eduardo Robinson. Fotoetnografia da Biblioteca Jardim. Porto Alegre: EDUFRGS, 2004.

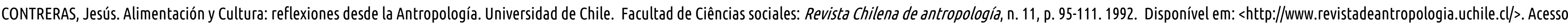
em: 3 ago. 2016.

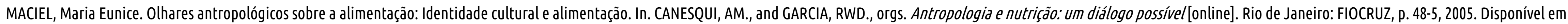
<http://books. scielo.org . Acesso em: 12 fev. 2016.

PICANÇO, Miguel de Nazaré Brito. Na roça, na mesa, na vida: uma viagem pelas trajetórias da mandioca, no e além do nordeste paraense. Belém: Paka-Tatu, 2018.

SAMAIN, Etienne. Como pensam as imagens. Campinas, SP: Editora da Unicamp, 2012.

SAMAIN, Etienne. O fotográfico. São Paulo: Hucitec/senac, 2005.

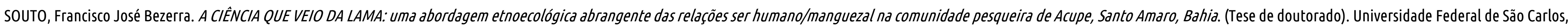
Programa de pós-graduação em Ecologia e recursos Naturais: 2004. 
